International Journal of Engineering \& Technology, $7(2.29)(2018) 1102-1106$
International Journal of Engineering \& Technology
SPC
Website: www.sciencepubco.com/index.php/IJET
Research paper

\title{
Satisfaction Level of Mobile Application Implementation Towards Passengers: an Analysis
}

\author{
Zirawani B. ${ }^{1 *}$, Fatimah Z. H. ${ }^{2}$, Syazwa N. M. R. ${ }^{3}$ \\ ${ }^{1,2,3}$ Universiti Kuala Lumpur, Malaysian Institute Of Industrial Technology, \\ Jalan Persiaran Sinaran Ilmu, Bandar Seri Alam, 81750 Johor Bahru, Johor, Malaysia \\ *Corresponding Author E-Mail:Zirawani@Unikl.Edu.My
}

\begin{abstract}
Taxi is become one of the most popular public transportation, especially in urban area. People may choose their public transports due to the comfortability, speedy and the efficiency. The mobile application is introduced in the way to create an easiness of booking matters in improving their system and target passengers. This technology of mobile apps is supposedly made convenient to the people with the booking system, which are able to fulfil all the requirements as demand by passengers. However, many mobile apps especially for booking system, there are still weaknesses, here and there. There are traffics while peak and off-peak hour. The system is jammed, passengers could not book and worse than that is the taxi's driver could not respond at all. Therefore, this research is very important to define all the factors contribute to those matters, in the way to purpose the robust mobile booking system for public transportation. Together with that, the satisfaction level factors towards the passenger's satisfaction on taxi services apps are analysed and verified. The research survey of questionnaire was designed to gain the primary data of respondents and been analysed using ANOVA in SPSS software. Findings of this research, hopefully can direct any others companies suite to this situation for a better mobile apps development.
\end{abstract}

Keywords: Satisfaction level; Taxi services applications; Analysis

\section{Introduction}

Public transportation in Malaysia is increasing and expanding to fulfil the demand of customers to travel from one place to another [1]. Public transportation plays a big role in the transportation industry that is becoming as an option for a person to move and improve an infrastructure, to provide mobility for those who need, create better transport planning and also to reduce congestion that will contribute into pollution to the earth. The better for the environment and safer, public transport is the best option, when available and practical in taking into account the nature of your journey, whether you can organize a day around fixed timetables, and whether you are feeling sociable [2].

Based on the survey conducted by The Expat in a June 2008, it is estimated 200 foreigners from around 30 countries, Malaysia taxis were found in providing the lowest ranking in services from 23 countries based on the survey. Majority of the respondents gave bad impression to Malaysian taxi drivers. From the LondonCabs.co.uk, Malaysia's taxis services are the top one of the worst drivers in the world. On top of that, passengers often encounter rude taxis that refuse to use the meter and charge extra rates. The behaviour of the offending taxis drivers has tarnished the image of Malaysia.

Demand of public transport in Johor Bahru area also increases based on the economic location and population growth. It is because taxi service apps is more comfortable and easy to access any destinations compare to buses. Another reason, few people do not like to wait for public transportation. They choose to use taxi to reduce waiting time. Nowadays, passengers can trace the taxis with the application in smartphone. That application is easy to trace the rates of charge when using the taxis. They can also access driver's information when using the taxis services apps. This paper endeavours to fill the gap in the factors which determine customer satisfaction by exploring the analysis of the passenger level of satisfaction of using the mobile application on taxi services. The case study are investigated at MyTeksi Sdn Bhd.

\section{Literature Review}

There are several issues and topics discussed in comprehensive review include the main application of this study, MyTeksi as a brief, the technology used, the online booking system and the customer satisfaction elements.

\subsection{MyTeksi}

MyTeksi is a Malaysian start up that aims to revitalize the taxi industry. That want to improve the safety and efficiency of town taxis by leveraging on advancements in GPS and mobile technology. MyTeksi application is mobile application system for Android Operating System, IPhones Operating System (IOS) also Windows Operating System. This application is a mobile application that helps customers to deliver taxi calling requests to taxi drivers through the application. With an application, it can assist the user to encounter the problem. MyTeksi is available in 24 hours days and most of these fares are based on the meters. MyTeksi was established in few countries such as Malaysia, Singapore, Thailand, Philippines, Vietnam and Indonesia. Some of countries, this taxi services application are also known as GrabTaxi. 
MyTeksi is the new development in Malaysia around 2012, which provides reliable online taxis application booking facility to people in various cities in Malaysia. MyTeksi acts like a bridge between the taxi operators and the passengers who book a cab. This is the online taxis application booking service provided to passengers as shown in Figure 1. This brings together the registered tax operators, cab owners and the customers. Here the customers can book a taxi by viewing all the taxi details and pricing details available, according to selected city and area. It is the reliable service provided to both customers and taxi operators. This provides service with well-conditioned of new vehicles, with experienced drivers for a happy journey of the customers.

\subsection{Technology Systems}

Information system can be definite as a set of interrelated components that collect, store, process and help analyse and support decision making. Information technology consist of a combination of human, hardware, software, networks and data, to establish, collect, convert and distribute information within an organization [3]. Identified that personal computers, mobile phone and the internet are dominant the world in technology is divided into five types [4]:

- Tangible: blueprint, models, operating, manuals, prototypes.

- Intangible: consultancy, problem-solving and training method. High entirely or almost entirely automated and intelligent technology that manipulates refined matter and medium level forces.

- Intermediate: semi-automated partially intelligent technology that manipulates refined matter and medium level forces.

- Low: to labour-intensive technology that manipulates only coarse or, gross, matter and weak forces.

Information Technology (IT) has significantly changed the way we live and work. Based on that journal, the significant aspect when to integrated the application system information are friendly user, fulfil the requirement of user and easy to use.

\subsection{Online Booking Systems.}

Online taxi booking service function are different with the current taxi booking system. This service can be accessed by customer's mobile devices with GPS capability [5]. Taxi online booking systems can make more improvement customer satisfaction by reducing taxi waiting time and visualizing the approaching taxi on map. MyTeksi acts like a bridge between the taxi operators and the passengers who book a taxi.

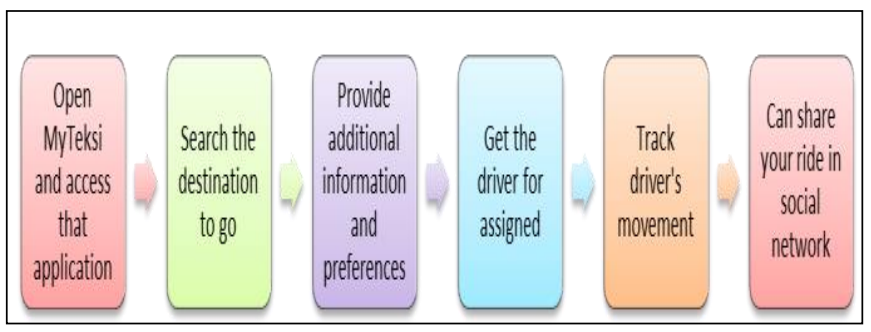

Fig. 1: Steps to using MyTeksi application

\subsection{Customer Satisfaction}

Customer satisfaction is defined as a core component in customer services and occupies a fundamental spot in marketing thought and practice, the major issue of marketing activity and helps to link processes culminating in purchase and consume with postpurchase phenomena such as attitude change, repeat purchase and brand commitment [6]. Service quality has a positive effect on overall satisfaction [7]. On here, MyTeksi driver provider should give a best service quality to attract people on using MyTeksi application. Satisfaction results when performance meets or exceeds expectations and dissatisfaction results when performance falls below expectations [8].

\subsection{Customer Service}

Customer service is one of the key dimensions for any business format to be successful. Online booking system such as e-ticketing also can declare as one of the part e-business. Online businesses have to rely on excellent customer service to be competitive [9]. Another dimension of customer service is delivery of the products or services [10], which that focus on an online retailer's delivery system including delivering the correct products or services also that receiving an order in good condition. The develop scales of customer service, fulfilment or reliability, together as once single concept, which was defined as first the accurate display and description of a product so that what customer receives is what they thought they ordered and second delivery of the right product or service within the right time at the right place with right of quantity [11].

\subsection{Fares}

Fare regulation is commonly applied to protect passenger from taking advantage due to the disseminated nature of the transaction, and the managerial difficulties of providing for differential entree to crowded taxi service. The provision of information to first time users of the taxi system is important to address the imbalance of information and the frequently voice concern of tourist. On simple observation by researcher, fares play the role as important factor on customer satisfaction to use the taxis. This is because more than ten percent of household spent more than $15 \%$ of their income on journey only for work [12]. This is maybe because of increasing the price of oil at global market because the expenditure on private vehicle also increases. Different with others researcher has said in Malaysia especially in the Klang Valley, people spent between $7 \%$ until $10 \%$ of their income on the taxi. This is proven that using taxi will bring more benefits to passengers than using their own private vehicle [13].

\subsection{Waiting Time}

The demand of taxis service from passenger not only depends on the price but also based on the waiting time. The excess capacity in empty taxi is not necessarily wasteful but in fact may be socially desirable, it increase the value of the service through the lower waiting times [14]. For the taxis driver, prefer their vehicles to be occupied by passenger that can pay the fare as much of possible of time. The customer is not demanding for quality, but they also demand for speed. As the standard of living in progressive countries increase, the value of the customer's time, increase and consequently they seek out those goods and services which will minimize the expenditure of their time. Thus, the customer can't wait in line for long periods of time just because to buy whatever products or services unless that thing is very important or that things is worthwhile to wait.

\subsection{Responsive}

Responsiveness is one of a key customer issue when using online booking on the web. This construct relates to responses from the Internet stores, when customers have questions or run into problems. For instance, the website can provide prompt service, helpful guidance, and accurate information about the products or services [15]. Responsiveness is one of the most frequently cited services quality dimensions that lead to satisfaction. The responsiveness of web based services has highlighted the importance of perceived quality of service and customer satisfaction [16]. Rresponsiveness are important for both overall quality of service and satisfaction [17].

\section{Methodology}

To find if passengers are satisfied with the products and services they are receiving, an organization must implement a metric for 
tracking customer satisfaction. This can be done by using a questionnaire. The questionnaire is an instrument for measuring 'gap' customer's satisfaction of the service they receive of the service. Primary data was collected and the respondents of the study were focus on taxi passengers who booking taxi service via MyTeksi applications. There include Malaysian people and international people in Johor Bahru area.

The data collected from questionnaire survey will be analysed through ANOVA in statistical package for social sciences (SPSS) software. After gather all the data, the data needs to be input into the software in order to get end results or output. The data will be interpreted into descriptive data, correlation and mean. Figure 2 represents the flow of the methodology of this study. The respondents of the study were focus on taxi passengers who booking taxi service via MyTeksi applications. There include Malaysian people and international people in Johor Bahru area. People tend to use this application as one of the best alternative for reservation the service early on time. The population of MyTeksi users at Johor Bahru area are 950.

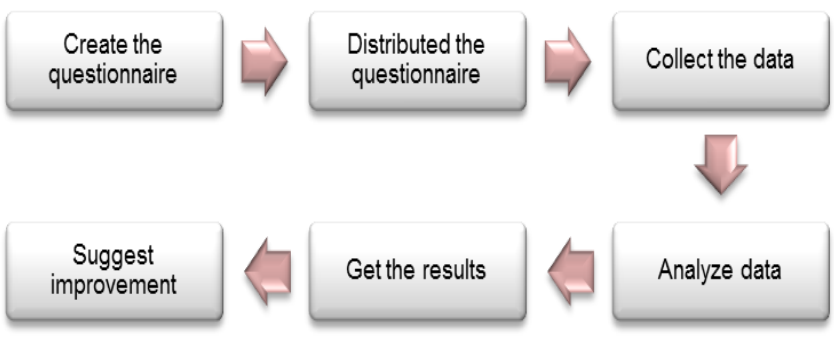

Fig. 2: The methodology process

\section{Empirical Findings}

According the survey that was making to know the level of satisfaction taxi service in Johor Bahru area. These surveys involve two selected area that are Larkin central and JB central. This survey involves three sections section A and section B. Part A consists of five demographic variables investigated in this study. There are gender, age, race, profession, marriage status, frequency the passenger use the MyTeksi application service and reasons to use MyTeksi application. The demographics of the final sample are shown in Table 1 . The majority of the respondents $(58.9 \%)$ were female and almost half (50\%) from Malay, age around 22-25 years $(41.1 \%)$ and majority $(42.2 \%)$ are students.

Figure 3 show the frequency of MyTeksi passengers that implement this mobile application in Johor Bahru area. Figure 4 until Figure 14 have a set of statements relate to respondent passengers satisfaction using LIKERT scaling. In section B has a few statements relate with the passengers satisfaction level. The statement is respondent base on the respondent overview about MyTeksi application in Johor Bahru area.

Table 1: Demographic sample

\begin{tabular}{|c|c|c|}
\hline Items & Details & Percentage (\%) \\
\hline \multirow[t]{2}{*}{ Gender } & \multirow{2}{*}{$\begin{array}{c}\text { Male } \\
\text { Female }\end{array}$} & $41.1 \%$ \\
\hline & & $58.9 \%$ \\
\hline \multirow[t]{4}{*}{ Race } & \multirow{4}{*}{$\begin{array}{l}\text { Malay } \\
\text { Chines } \\
\text { Indian } \\
\text { Others }\end{array}$} & $50 \%$ \\
\hline & & $21.1 \%$ \\
\hline & & $15.6 \%$ \\
\hline & & $13.3 \%$ \\
\hline \multirow[t]{4}{*}{ Age } & \multirow{4}{*}{$\begin{array}{c}18-21 \\
22-25 \\
26-29 \\
30 \text { and above }\end{array}$} & $30 \%$ \\
\hline & & $41.1 \%$ \\
\hline & & $17.8 \%$ \\
\hline & & $11.1 \%$ \\
\hline \multirow{4}{*}{ Profession } & Student & $42.2 \%$ \\
\hline & Executive & $28.9 \%$ \\
\hline & Non-executive & $13.3 \%$ \\
\hline & Others & $15.6 \%$ \\
\hline
\end{tabular}

FREQUENCY OF PASSENGERS USE MYTEKSI AF

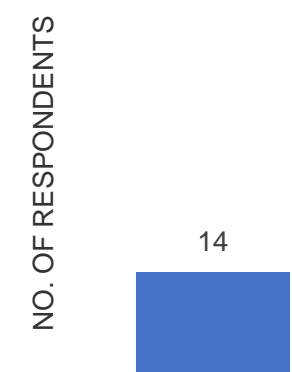

Fig. 3: Frequency of passengers use MyTeksi application

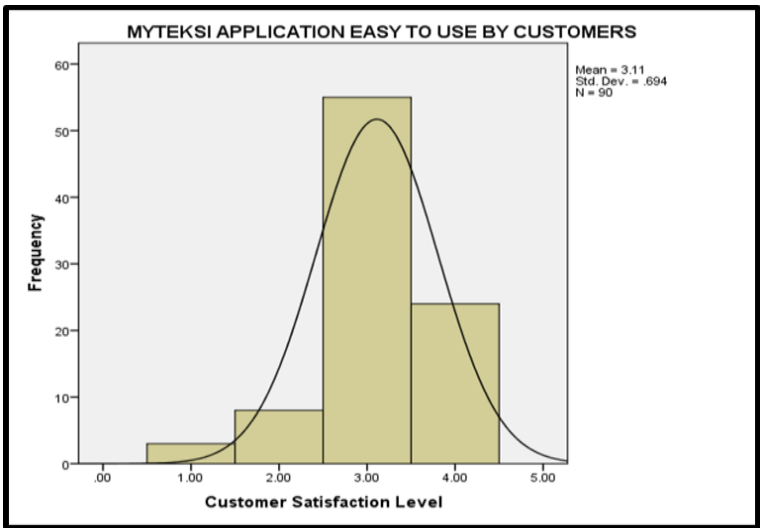

Fig. 4: Histogram and skewness of represents MyTeksi application easy to use by customers

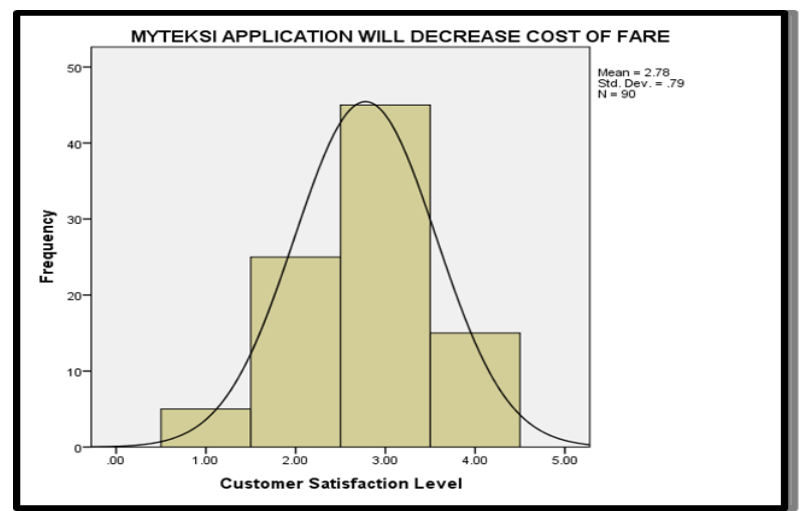

Fig. 5: Histogram and skewness of represents MyTeksi will decrease cost of fare

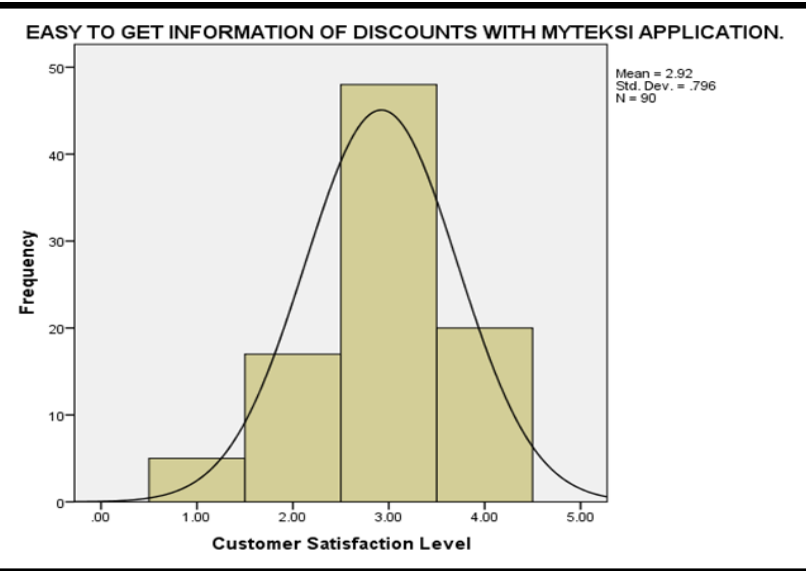

Fig. 6: Histogram and skewness of represents easy to get information of discount with MyTeksi application 


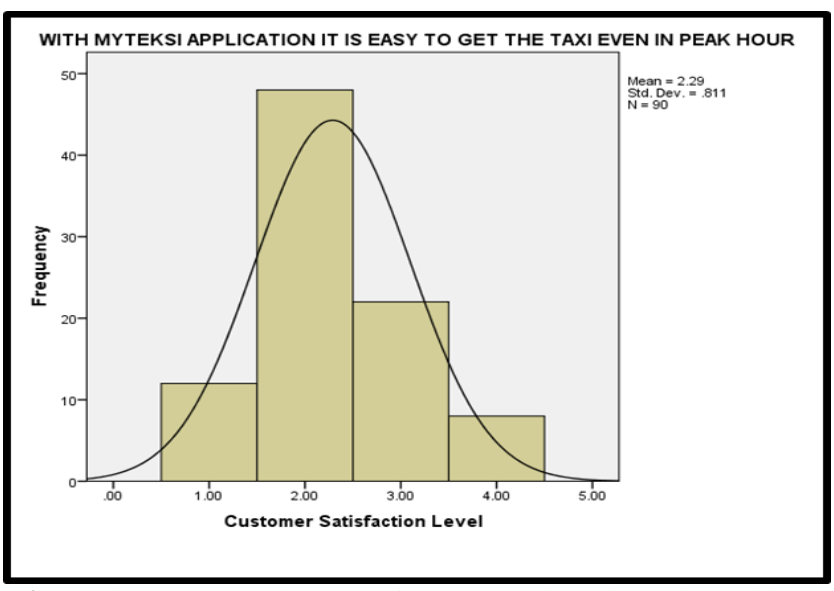

Fig. 7: Histogram and skewness of easy to get the taxi even in peak hour

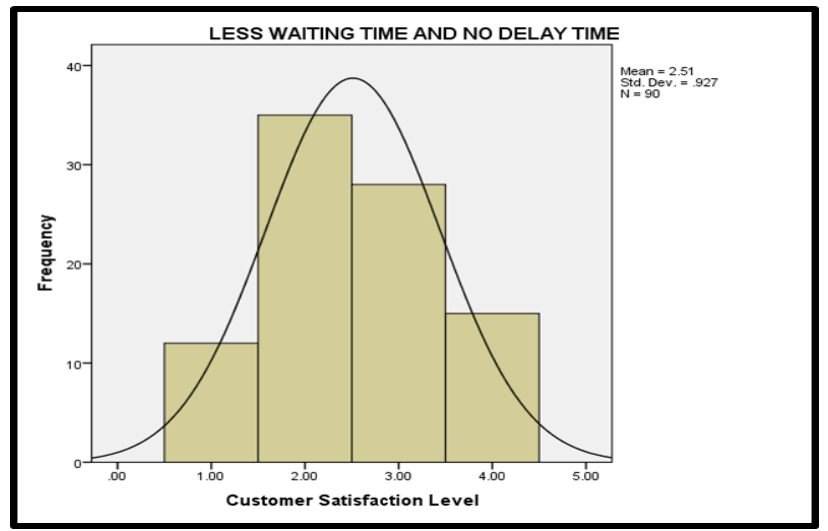

Fig. 8: Histogram and skewness of represents less waiting time and no delay time

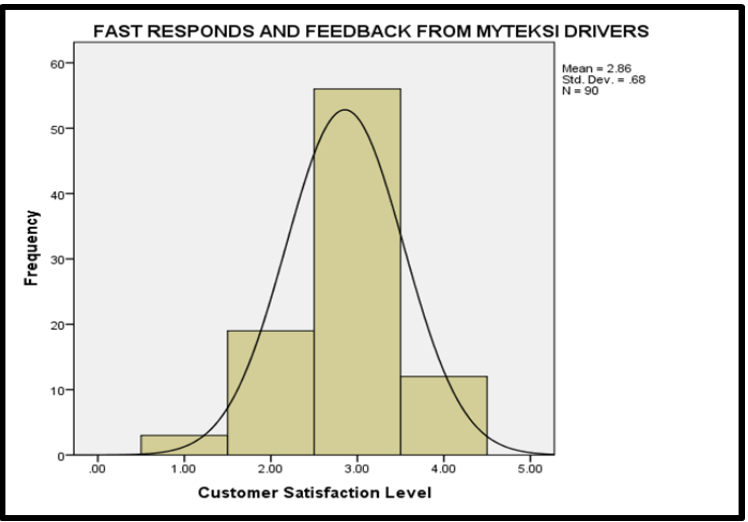

Fig.9: Histogram and skewness of represents fast respond and feedback from MyTeksi drivers

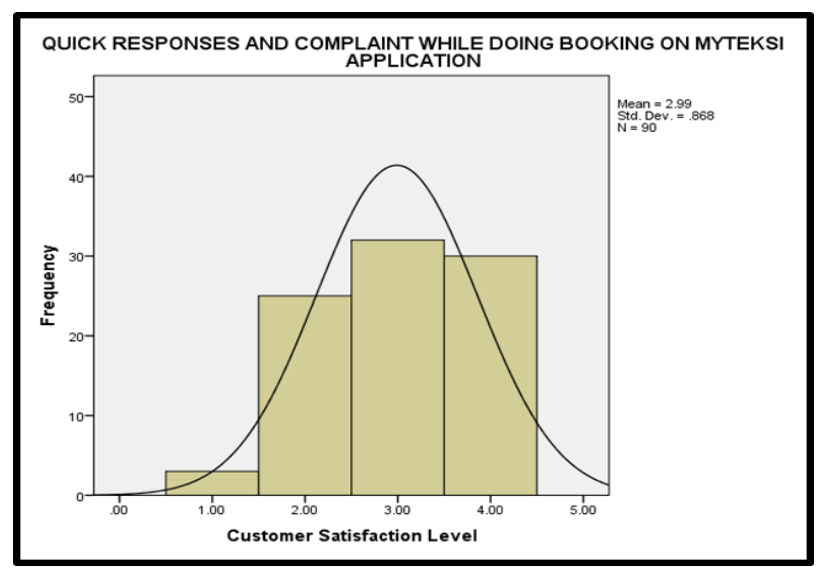

Fig. 10: Histogram and skewness of quick responses and complaint while use MyTeksi application

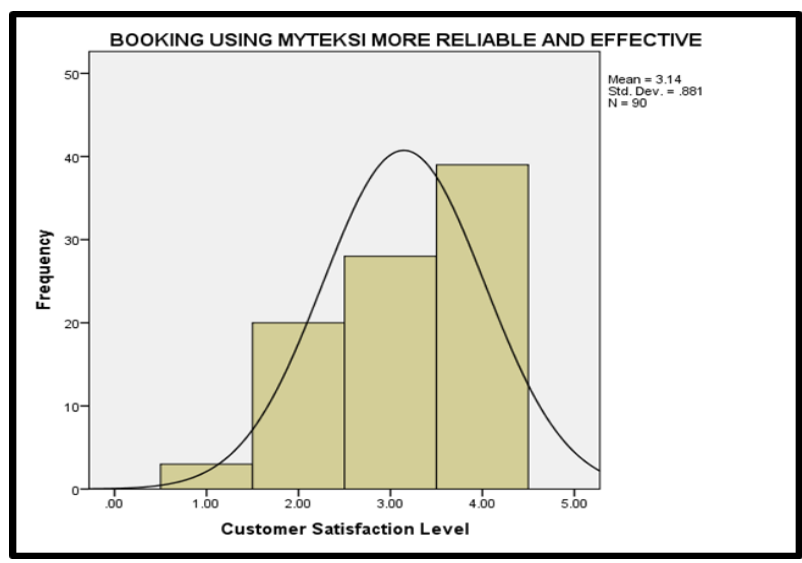

Fig. 11: Histogram and skewness of represents booking using MyTeksi more reliable and effective

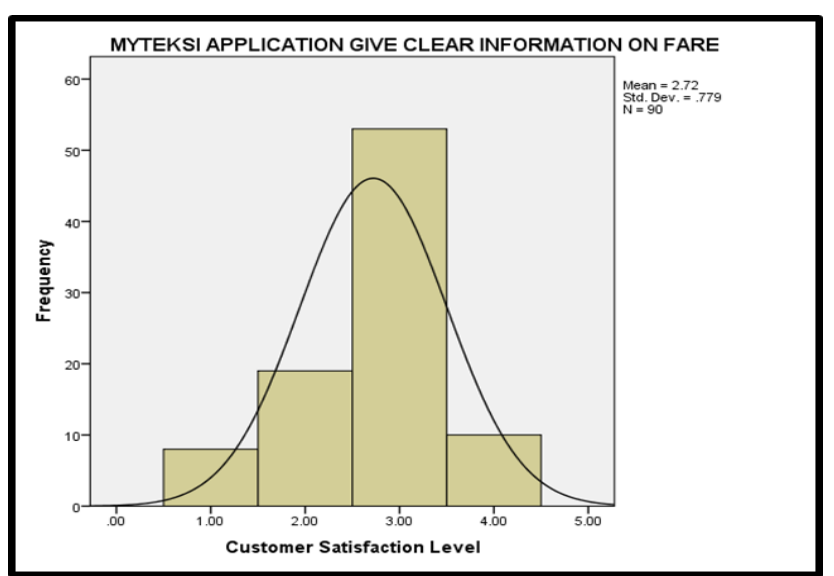

Fig. 12: Histogram and skewness give clear information on fare

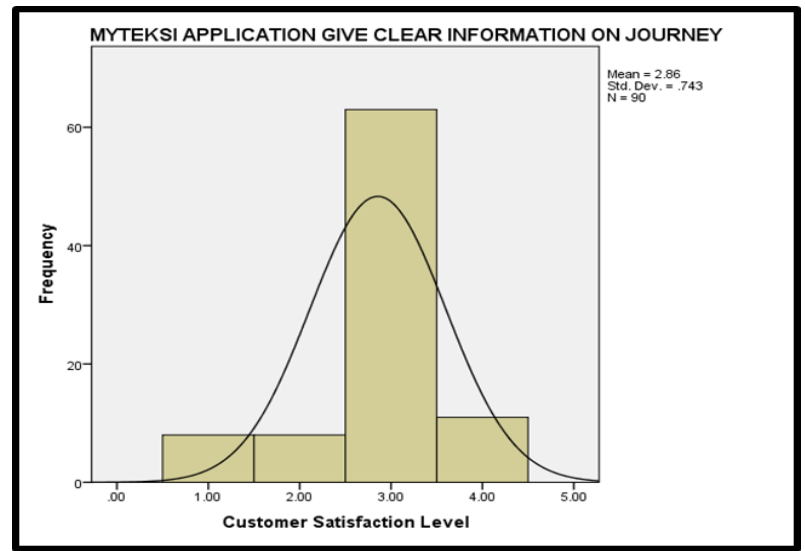

Fig.13: Histogram and skewness give clear information on journey

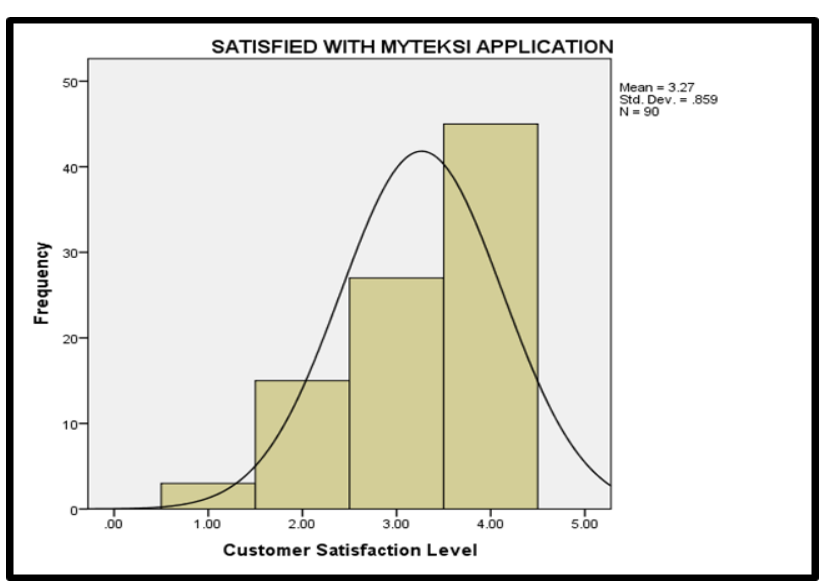

Fig.14: Histogram and skewness of represents respondents satisfied with MyTeksi application 
Overall, the findings of the research suggest that a solution to enhance the level of satisfaction must be found to improve the MyTeksi application especially in time peak hour. The result shows the level of customer satisfaction which depends a few factors such as fare, easy to access, and individual attention. From that, it can determine which aspect is very important for customer.

\section{Conclusion}

This paper analysed the satisfaction level of MyTeksi implementation towards passengers at Johor Bahru area. The feedback of satisfaction was obtained through questionnaire survey. According to the questionnaire responds and analysis, overall factors that show the highest frequency are determined. Generally, respondents are satisfied while using MyTeksi application but not in the time processing of MyTeksi, especially while peak hour. MyTeksi application can help passenger get taxi service in a peak hour and less waiting time or delay time when using the MyTeksi applications. MyTeksi Sdn. Bhd. needs to improve in several ways so that it will satisfy the customer. As for the passengers satisfaction factors, the relationship between each factor has strong relationship. This survey results were discussed. Finally, recommendation has been made to parties implementation to accomplish satisfaction level of passengers at Johor Bahru.

\section{References}

[1] Nursitihazlin, A. T. (2006). The Fatality Index of Public Transport (Express Bus) in Malaysia.

[2] Crabtree, V. (2007). Public Transport is good. The Advantages of Pooled Transport... www.vexen.co.uk. Retrieved 4 March 2015, from http://www.vexen.co.uk/notes/public_transport.html

[3] Chatterjee, I. (2010). Management information systems. New Delhi: PHI Learning.

[4] Schwanen, T., Dijst, M., \& Kwan, M. (2006). Introductionâ€"The Internet, Changing Mobilities, and Urban Dynamics. Urban Geography, 27(7), 585-589.

[5] Wang, H., Cheu, R., \& Lee, D. (2014). Intelligent Taxi Dispatch System for Advance Reservations. Journal of Public Transportation 17(3), 115-128.

[6] Abd.Aziz, S., Would waiting time influences customer satisfaction towards services patronage? A study of lembaga tabung haji. Research report, $1-34$.

[7] Wen Tai Lai and Ching Fu Chen (2010). Behavioral Intentions of Public Transit Passengers: The Roles of Service Quality, Perceived Value, Satisfaction and Involvement, ISSN 0967-070X

[8] Burns, G. N., \& Bowling, N. A. (2010). Dispositional approach to customer satisfaction and behavior. Journal of Business and Psychology, 25(1), 99-107.

[9] Lennon, R., \& Harris, J. (2002). Customer service on the Web: A cross-industry investigation. J Target Meas Anal Mark, 10(4), 325338.

[10] Francis, J. E., \& White, L. (2004). Internet retailing: Back to the future.

[11] Wolfinbarger, M., \& Gilly, M. (2003). eTailQ: dimensional zing, measuring and predicting etail quality. Journal of Retailing, 79(3), 183-198.

[12] A.T Amstrong Wright (1986). Road pricing and User Restraint: Opportunities and Constraints in Developing Countries, Volume 20 Issue 2, March 1986, Pages 123-127.

[13] Zakaria, A. (2001). Sistem Perkhidmatan Bandar 'Dalaman dan Luaran': Satu Kajian Kes, Proceedings of the Eastern Asia Society for Transportation Studies, Vol.9, 2013 CAP National Seminar, Changing Directions: Towards Sustainable Transport in Malaysia, September

[14] Flores-Guri, D. (2003). An Economic Analysis of Regulated Taxicab Markets. Review of Industrial Organization, 23(3/4), 255-266.

[15] Parasuraman, A., Zeithaml, V. A., \& Malhotra, A. (2005). ES QUAL a multiple-item scale for assessing electronic service quality Journal of service research, 7(3), 213-233.

[16] Xue, M., \& Harker, P. T. (2002). Customer efficiency concept and its impact on e-business Management. Journal of Service Research, 4(4), 253-267.

[17] Yang, Z., Jun, M., \& Peterson, R. (2004). Measuring customer perceived online service quality. Int Jrnl of Op \& Prod Mnagemnt, 24(11), 1149-1174. 